\title{
Green Fabrication of A Multifunctional Sponge as Absorbent For Highly Efficient and Ultrafast Oil-Water Separation
}

Xiaomeng Shi ${ }^{1}$, Yanrong Lan ${ }^{1}$, Shan Peng ${ }^{1,2 *}$, Yingchun Wang ${ }^{1,2}$, Jing Ma ${ }^{1,2 *}$

1 College of Chemistry and Environmental Science, Hebei University, Baoding 071002, Hebei, China

2 Engineering Technology Research Center for Flame Retardant Materials and Processing Technology of Hebei Province, Key Laboratory of Analytical Science and Technology of Hebei Province, Hebei University, Baoding, 071002, China

Corresponding author. E-mail: psghbu@126.com

Phone: (+86)15013038214 


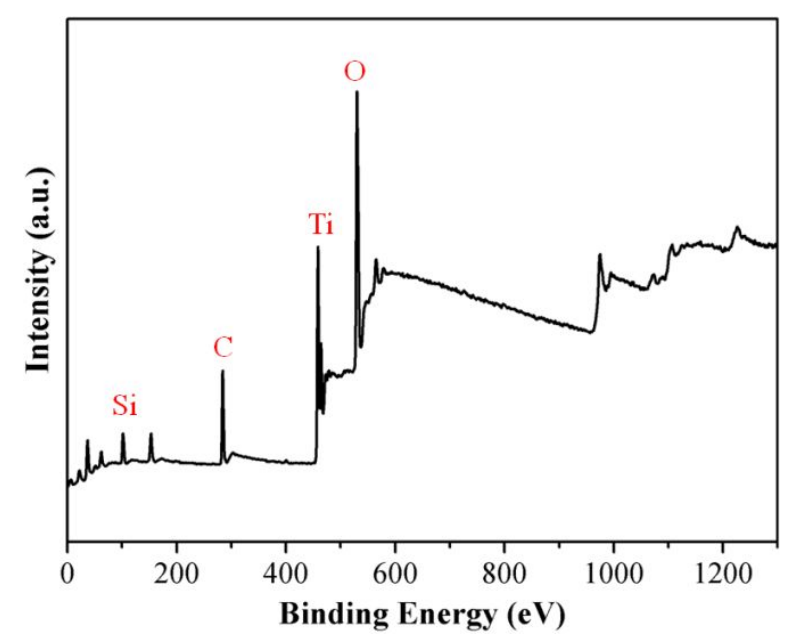

Figure S1. The XPS survey data for the PDMS grafted $\mathrm{TiO}_{2}$ powders.
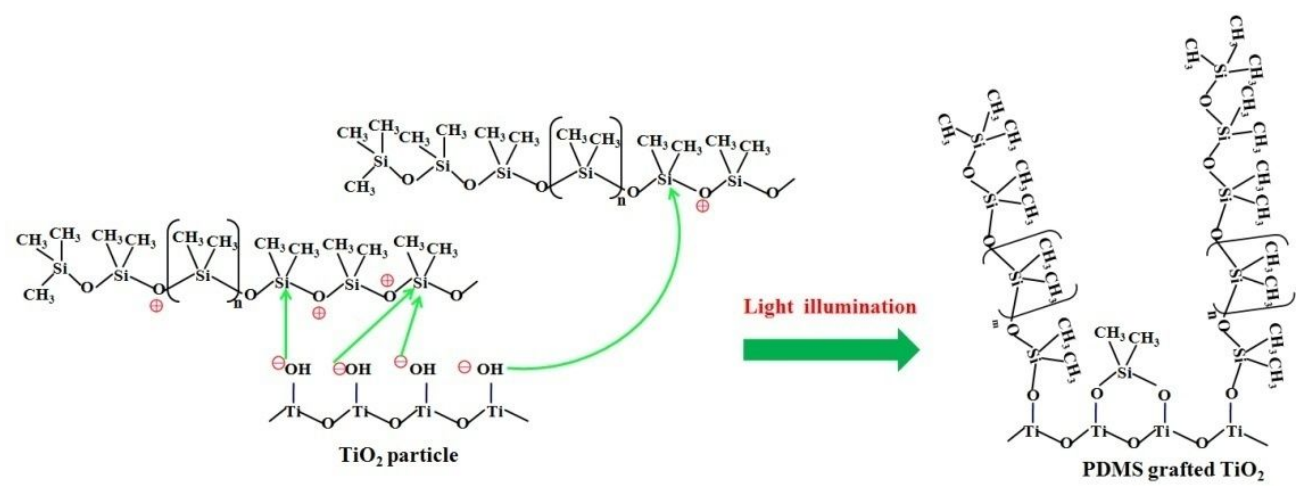

Figure S2. Mechanism illustrations for the grafted reactions between the PDMS and the $\mathrm{TiO}_{2}$ particles.

Table S1 Summarization of BET data for various samples

\begin{tabular}{|c|c|c|}
\hline Sample & Pore volume $(\mathrm{cc} / \mathrm{g})$ & Surface area $\left(\mathrm{m}^{2} / \mathrm{g}\right)$ \\
\hline $\mathrm{AC}$ & 0.154 & 350.2 \\
\hline $\mathrm{AC}-\mathrm{TiO}_{2}$ & 0.171 & 336.3 \\
\hline $\mathrm{AC}-\mathrm{TiO}_{2}$-PDMS & 0.159 & 321.1 \\
\hline
\end{tabular}




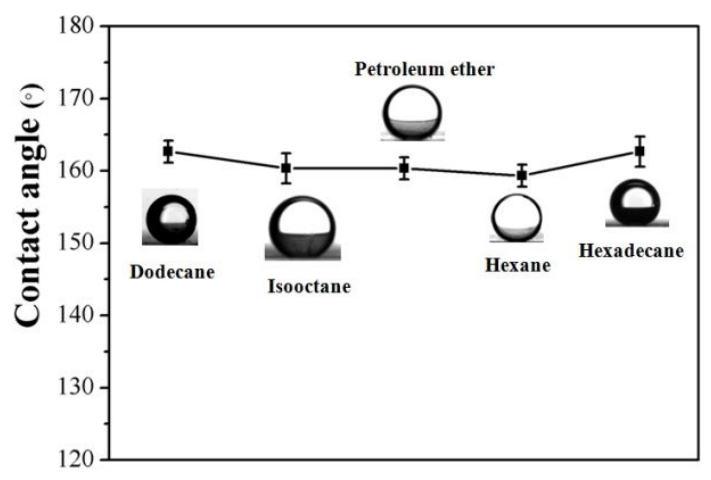

Figure S3. The coated sponge also showed superhydrophobicity under various oils (include dodecane, isooctane, petroleum ether, hexane, and hexadecane).
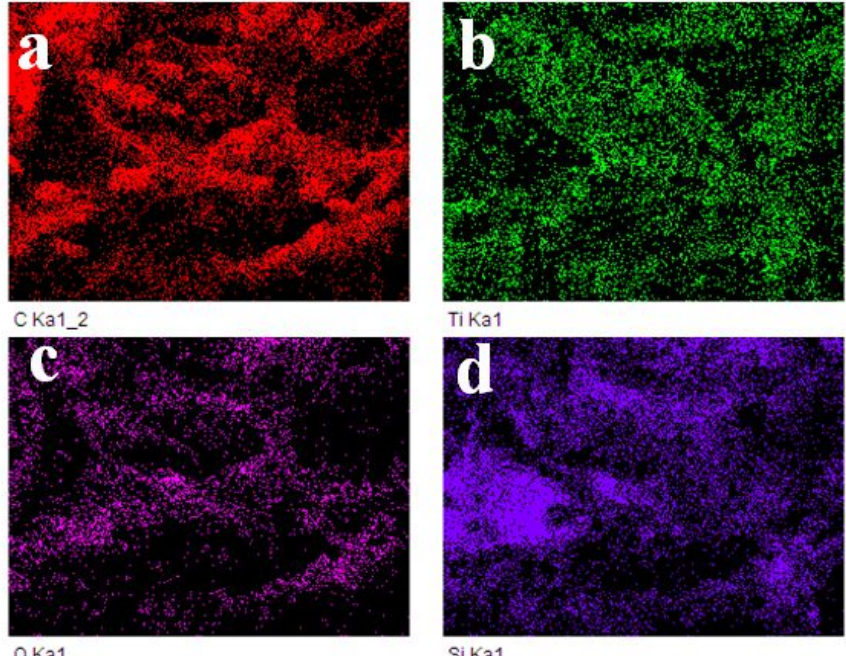

Figure S4. (a-d) EDS mapping images of elements C, Ti, O, and Si.

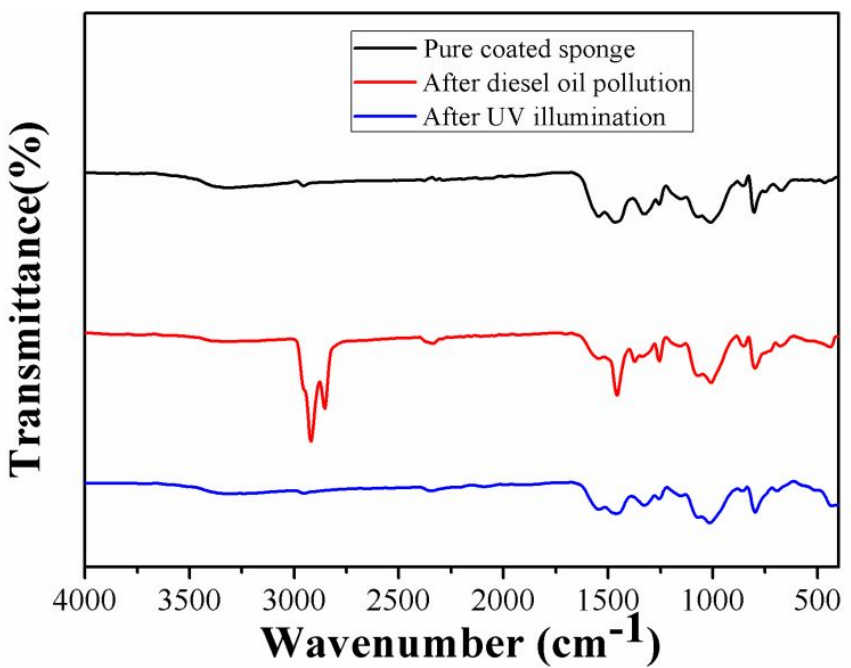

Figure S5. The FTIR spectra for the pure coated sponge, the diesel oil-polluted coated sponge, and the diesel oil-polluted coated sponge after UV illumination. 


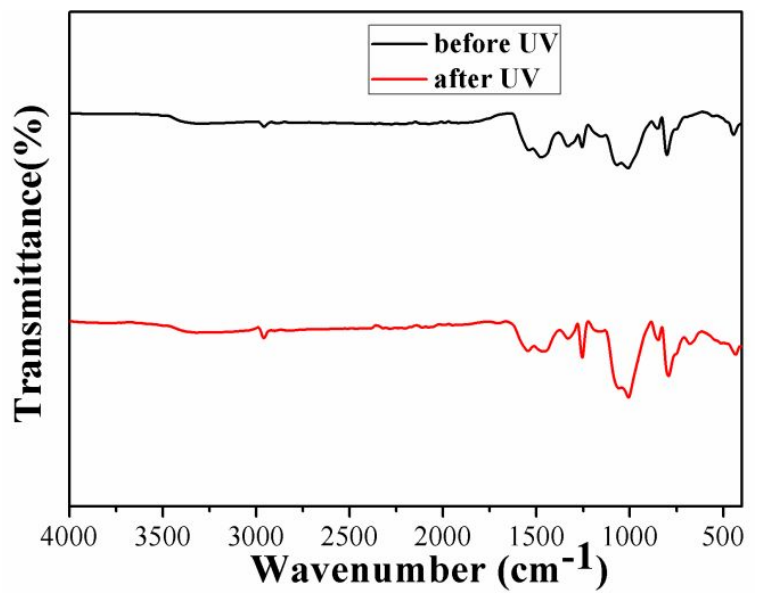

Figure S6. The FTIR spectra for the coated sponge before and after UV illumination (10 h).

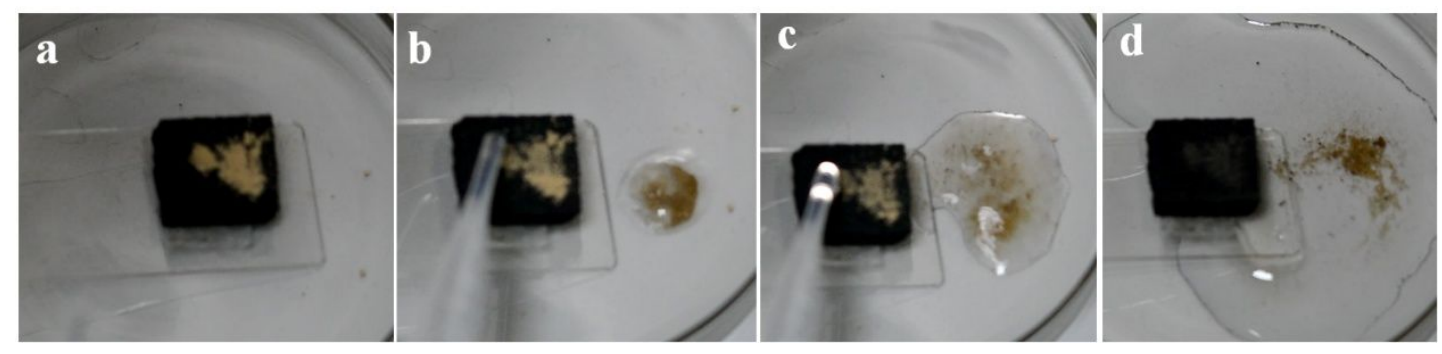

Figure S7. (a-d) Self-cleaning tests of the coated sponge

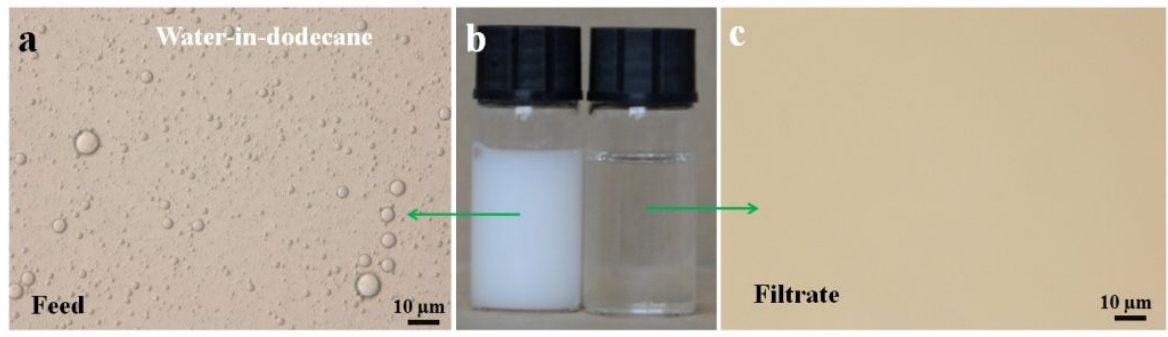

Figure S8. The coated sponge could be used to separate water-in-dodecane emulsion, which was emulsified by Span- 80 . The surfactant concentration here was $2 \mathrm{mg} / \mathrm{mL}$. (a) the optical image for the emulsion before separation. (b) pictures of the emulsion before and after separation. (c) the optical image for the emulsion after separation. 